\title{
Correlation Analysis of Behavioral Factors of Construction Safety Based on the Chi-square Test
}

\author{
Sun Kaichang ${ }^{1, a}$, Zhou Jianlan ${ }^{2, b}$, Sun Zhiyu ${ }^{3, c}$ and Li Kun ${ }^{4, d}$ \\ ${ }^{1}$ College of Hydraulic \& Environmental Engineering, China Three Gorges Univ., Yichang 443002, \\ China \\ ${ }^{2}$ Department of Control Science \& Engineering, Huazhong University of Science and Technology, \\ Wuhan, 430074, China \\ ${ }^{3}$ Department of Science \& Environmental Protection, China Three Gorges Group. Yichang 443002, \\ China \\ ${ }^{4}$ College of Civil Engineering \& Architecture, China Three Gorges Univ., Yichang 443002, China \\ asunkaichang@gmail.com, bzhouj11999@163.com, csun_zhiyu@yahoo.com, \\ dikun2408@gmail.com
}

Keywords: chi-square test; construction safety; behavioral factors; relationship analysis

\begin{abstract}
The construction safety supervision errors can lead to unsafe behavior; further affect the working conditions of workers and result in accidents at last. The probabilities of data are provided by statistical analysis between the different types of neighborhood-level factors by the independence of the chi-square test. The relationship analysis of the independence between the behavioral factors has been performed in order to find the non-independent factors. Among the Human Factors Analysis and Classification System (HFACS), the impact of the high-level factors on the bottom level is determined. Based on the data, the work path of various factors in the HFACS frame is confirmed and it can be a reference for the development of the preventive measures.
\end{abstract}

\section{Introduction}

Human Factors Analysis and Classification System (HFACS) can make a preliminary classification of accident which leads by behavioral factors. But this is only a static analysis [1]. Dekker indicated that HFACS just classify the behavioral factors in the accident simply. It does not show how the upper factors affect the lower and the measures to avoid accidents in the future [2]. So the analysis for relationship of factors between adjacent layers in HFACS frames is indispensable. Such analysis is benefit for developing security measures for specific factors. It can also inhibit the occurrence of chain-reaction leads by the factors [3,4].

\section{Amendment of HFACS}

In order to adapt to the hydraulic project, some amendments has been done according to HFACS. The details are shown in the following. L4 means Influence of Enterprise which includes resource management, safety culture and organizational processes. L3 means Safety Supervision which includes insufficient supervision (training), inappropriate scheduling, rectification is not hidden and management irregularities. L2 means Precondition for Unsafe Acts which includes operating environment, technical measures, team management and the quality of personnel. L1 means Unsafe Behavior of Construction Workers which includes perception and decision-making errors, skill errors and illegal operation. The factors in the new HFACS framework revised have been selected again according to the Construction characteristics. In the hydraulic engineering construction, one of the purposes of application of HFACS framework is to determine the factors which are relatively important part of the totals in the occurred incidents as quickly as possible. Hence, human and material resources can focus on rectification of the problems which reflected by the factors. After the adjustment of factors of Standard HFACS framework, it is possible to reflect the actual situation of hydraulic projects more reasonably by strengthening the independence and general. 


\section{Chi-square test and its application}

The classification statistics of human factors in accident are described in this study. They are of categorization of variables, so the chi-square test is applied. Based on the theoretical numbers, the chi-square distribution is to measure the deviation between the actual and the theoretical numbers, respectively. It can be described by Eq. 1 .

$$
\chi^{2}=\sum\left[\frac{\left(\mathrm{f}_{0}-\mathrm{f}_{\mathrm{e}}\right)^{2}}{\mathrm{f}_{\mathrm{e}}}\right]
$$

Where, $f_{0}$ is the actual number of observations, $f_{\mathrm{e}}$ is the theoretical (expected) number of observations. In this study, the data which used are given in a table with two rows and two columns. The detailed test steps are as follows [5]. In the first, the original hypothesis and alternative hypothesis are put forward, respectively. In the second, the chi-square statistics are calculated by Eq.1 based on the Table 1.

Table 1 Calculated table for the chi-square statistics

\begin{tabular}{|c|c|c|c|c|}
\hline & & \multicolumn{2}{|c|}{ High-level factors } & \multirow{2}{*}{ Sum of rows } \\
\hline & & yes & no & \\
\hline \multirow{2}{*}{ low-level factors } & yes & $\mathrm{n}_{11}\left(\mathrm{f}_{11}\right)$ & $\mathrm{n}_{12}\left(\mathrm{f}_{12}\right)$ & $\mathrm{n}_{\mathrm{r} 1}$ \\
\hline & no & $\mathrm{n}_{21}\left(\mathrm{f}_{21}\right)$ & $\mathrm{n}_{22}\left(\mathrm{f}_{22}\right)$ & $\mathrm{n}_{\mathrm{r} 2}$ \\
\hline \multicolumn{2}{|c|}{ Sum of columns } & $\mathrm{n}_{\mathrm{c} 1}$ & $\mathrm{n}_{\mathrm{c} 2}$ & $\mathrm{n}(57)$ \\
\hline
\end{tabular}

In the Eq. $1, f_{0}$ is the $\mathrm{n}$ in the Table 1 which is the data of actual observations. The $\mathrm{f}$ in the brackets is $\mathrm{f}_{\mathrm{e}}$ in the Eq. 1 which is the theoretical data. The value of $\mathrm{f}$ is calculated by Eq.2.

$$
\frac{f_{i j}}{n_{c j}}=\frac{n_{r i}}{n} \Rightarrow f_{i j}=\frac{n_{r i} \cdot n_{c j}}{n}
$$

If $\mathrm{A}, \mathrm{B}, \mathrm{C}$ and $\mathrm{D}$ are used to represent the observations times in the Table 1, then the calculated equation for the chi-square statistics can be shown as Eq.3 [6].

$$
\chi^{2}=\frac{\mathrm{n}(A D-B C)^{2}}{(A+B)(C+D)(A+C)(B+D)}
$$

In the third, based on the degrees of freedom and significance level $\alpha$, the critical value of $\chi_{\alpha}^{2}$ is obtained. Then by comparing the statistics of $\chi^{2}$ with $\chi_{\alpha}^{2}$, the results are obtained.

\section{Correlation analysis by Chi-square test}

The original hypothesis $\mathrm{H}_{0}$ is that two variables are independent and the alternative hypothesis $\mathrm{H}_{1}$ is that two variables are not independent. The correlation analysis is done from high-level adjacent to the lower level between the factors. The significance level $\alpha$ is taken as 0.05 , so the $\chi_{0.05}^{2}=3.84$.

The first stage is the correlation analysis of the factors in $\mathbf{L} \mathbf{4}$ and $\mathbf{L 3}$. The complete calculation is

\begin{tabular}{|c|c|c|c|c|}
\hline & & \multicolumn{2}{|c|}{ Resource management } & \multirow{2}{*}{ Sum of rows } \\
\hline & & yes & no & \\
\hline \multirow{2}{*}{$\begin{array}{l}\text { Inadequate } \\
\text { supervision }\end{array}$} & yes & 4 & 49 & 53 \\
\hline & no & 0 & 4 & 4 \\
\hline \multicolumn{2}{|c|}{ Sum of columns } & 4 & 53 & $\mathrm{n}(57)$ \\
\hline \multicolumn{2}{|c|}{ Test results } & \multicolumn{3}{|c|}{$\chi^{2}=0.32, \quad \chi^{2}<\chi_{005}^{2}$, Independent } \\
\hline
\end{tabular}
given in the following.

Table 2 The correlation analysis result between L4 and L3 
Table 3 The correlation analysis result between L4 and L3

\begin{tabular}{|c|c|c|c|c|}
\hline \multicolumn{2}{|c|}{} & \multicolumn{2}{|c|}{ Resource management } & \multirow{2}{*}{ Sum of rows } \\
\cline { 2 - 5 } & yes & no & 9 \\
\hline \multirow{2}{*}{$\begin{array}{c}\text { Scheduling } \\
\text { inappropriate }\end{array}$} & yes & 2 & 7 & 48 \\
\cline { 2 - 5 } & no & 2 & 46 & $\mathrm{n}(57)$ \\
\hline \multicolumn{2}{|c|}{ Sum of columns } & 4 & 53 & \multicolumn{2}{c|}{$\chi^{2}=3.79, \quad \chi^{2}<\chi_{0.05}^{2}$, Independent } \\
\hline \multicolumn{2}{|c|}{ Test results }
\end{tabular}

Table 4 The correlation analysis result between L4 and L3

\begin{tabular}{|c|c|c|c|c|}
\hline \multicolumn{2}{|c|}{} & \multicolumn{2}{|c|}{ Resource management } & \multirow{2}{*}{ Sum of rows } \\
\cline { 2 - 5 } & yes & no & 14 \\
\hline \multirow{2}{*}{$\begin{array}{l}\text { Rectification } \\
\text { is not hidden }\end{array}$} & yes & 1 & 13 & 43 \\
\cline { 2 - 5 } & no & 3 & 40 & $\mathrm{n}(57)$ \\
\hline \multicolumn{2}{|c|}{ Sum of columns } & 4 & 53 & \multicolumn{2}{|c|}{$\chi^{2}=0.00045, \quad \chi^{2}<\chi_{0.05}^{2}$, Independent } \\
\hline \multicolumn{2}{|c|}{ Test results }
\end{tabular}

Table 5 The correlation analysis result between L4 and L3

\begin{tabular}{|c|c|c|c|c|}
\hline & & \multicolumn{2}{|c|}{ Resource management } & \multirow{2}{*}{ Sum of rows } \\
\hline & & yes & no & \\
\hline \multirow{2}{*}{$\begin{array}{l}\text { Management } \\
\text { irregularities }\end{array}$} & yes & 2 & 19 & 21 \\
\hline & no & 2 & 34 & 36 \\
\hline \multicolumn{2}{|c|}{ Sum of columns } & 4 & 53 & $\mathrm{n}(57)$ \\
\hline \multicolumn{2}{|c|}{ Test results } & \multicolumn{3}{|c|}{$\chi^{2}=0.32, \quad \chi^{2}<\chi_{0.05}^{2}$, Independent } \\
\hline
\end{tabular}

Table 6 The correlation analysis result between L4 and L3

\begin{tabular}{|c|c|c|c|c|}
\hline \multicolumn{2}{|c|}{} & \multicolumn{2}{|c|}{ Organizational processes } & \multirow{2}{*}{ Sum of rows } \\
\cline { 3 - 5 } \multicolumn{2}{|c|}{} & yes & no & 53 \\
\hline \multirow{2}{*}{$\begin{array}{c}\text { Inadequate } \\
\text { supervision }\end{array}$} & yes & 7 & 46 & 4 \\
\cline { 2 - 5 } & no & 0 & 4 & $\mathrm{n}(57)$ \\
\hline \multicolumn{2}{|c|}{ Sum of columns } & 7 & 50 & \multicolumn{2}{c|}{$\chi^{2}=0.60, \quad \chi^{2}<\chi_{0.05}^{2}$, Independent } \\
\hline \multicolumn{2}{|c|}{ Test results } &
\end{tabular}

Table 7 The correlation analysis result between L4 and L3

\begin{tabular}{|c|c|c|c|c|}
\hline \multicolumn{2}{|c|}{} & \multicolumn{2}{|c|}{ Organizational processes } & \multirow{2}{*}{ Sum of rows } \\
\cline { 2 - 5 } & yes & no & 9 \\
\hline \multirow{2}{*}{$\begin{array}{c}\text { Scheduling } \\
\text { inappropriate }\end{array}$} & yes & 2 & 7 & 48 \\
\cline { 2 - 5 } & no & 5 & 43 & $\mathrm{n}(57)$ \\
\hline \multicolumn{2}{|c|}{ Sum of columns } & 7 & 50 & \multicolumn{2}{c|}{$\chi^{2}=0.98, \quad \chi^{2}<\chi_{0.05}^{2}$, Independent } \\
\hline \multicolumn{2}{|c|}{ Test results }
\end{tabular}

Table 8 The correlation analysis result between L4 and L3

\begin{tabular}{|c|c|c|c|c|}
\hline \multicolumn{2}{|c|}{} & \multicolumn{2}{c|}{ Organizational processes } & \multirow{2}{*}{ Sum of rows } \\
\cline { 2 - 5 } & yes & no & 14 \\
\hline \multirow{2}{*}{$\begin{array}{l}\text { Rectification } \\
\text { is not hidden }\end{array}$} & yes & 4 & 10 & 43 \\
\cline { 2 - 5 } & no & 3 & 40 & $\mathrm{n}(57)$ \\
\hline \multicolumn{2}{|c|}{ Sum of columns } & 7 & 50 & $\chi^{2}=4.81, \chi^{2}>\chi_{0.05}^{2}$, Non-independent \\
\hline \multicolumn{2}{|c|}{ Test results } & \multicolumn{2}{|c|}{} \\
\hline
\end{tabular}


Table 9 The correlation analysis result between L4 and L3

\begin{tabular}{|c|c|c|c|c|}
\hline \multicolumn{2}{|c|}{} & \multicolumn{2}{|c|}{ Resource management } & \multirow{2}{*}{ Sum of rows } \\
\cline { 2 - 5 } & yes & no & 21 \\
\hline \multirow{2}{*}{$\begin{array}{l}\text { Management } \\
\text { irregularities }\end{array}$} & yes & 4 & 17 & 36 \\
\cline { 2 - 5 } & no & 3 & 33 & $\mathrm{n}(57)$ \\
\hline \multicolumn{2}{|c|}{ Sum of columns } & 7 & 50 & \multicolumn{2}{c|}{$\chi^{2}=1.41, \chi^{2}<\chi_{0.05}^{2}$, Independent } \\
\hline \multicolumn{2}{|c|}{ Test results }
\end{tabular}

It is indicated that the organizational processes and rectification which is not hidden are non-independent among the factors.

The second stage is the correlation analysis of the factors in $\mathbf{L 3}$ and L2. Due to limited space, only the correlation analysis of non-independent factors is given in the following.

Table 10 The correlation analysis result between L3 and L2

\begin{tabular}{|c|c|c|c|c|}
\hline \multicolumn{2}{|c|}{} & \multicolumn{2}{|c|}{ Inadequate supervision } & \multirow{2}{*}{ Sum of rows } \\
\cline { 3 - 5 } \multicolumn{2}{|c|}{} & yes & no & 49 \\
\hline \multirow{2}{*}{$\begin{array}{c}\text { The quality } \\
\text { of personnel }\end{array}$} & yes & 48 & 1 & 8 \\
\cline { 2 - 5 } & no & 5 & 3 & $\mathrm{n}(57)$ \\
\hline \multicolumn{2}{|c|}{ Sum of columns } & 53 & 4 & $\chi^{2}=13.25, \quad \chi^{2}>\chi_{0.05}^{2}$, Non-independent \\
\hline \multicolumn{2}{|c|}{ Test results } & \multicolumn{2}{|c|}{$\chi^{2}$}
\end{tabular}

Table 11 The correlation analysis result between L3 and L2

\begin{tabular}{|c|c|c|c|c|}
\hline \multicolumn{2}{|c|}{} & \multicolumn{2}{c|}{ Management irregularities } & \multirow{2}{*}{ Sum of rows } \\
\cline { 3 - 5 } & yes & no & \\
\hline \multirow{2}{*}{$\begin{array}{c}\text { Operating } \\
\text { environment }\end{array}$} & yes & 13 & 32 & 45 \\
\cline { 2 - 5 } & no & 8 & 4 & 12 \\
\hline \multicolumn{2}{|c|}{ Sum of columns } & 21 & 36 & $\mathrm{n}(57)$ \\
\hline \multicolumn{2}{|c|}{$\chi^{2}=5.81, \quad \chi^{2}>\chi_{0.05}^{2}$, Non-independent } \\
\hline
\end{tabular}

The third stage is the correlation analysis of the factors in L2 and L1. Due to limited space, only the correlation analysis of non-independent factors is given in the following.

Table 12 The correlation analysis result between L2 and L1

\begin{tabular}{|c|c|c|c|c|}
\hline \multicolumn{2}{|c|}{} & \multicolumn{2}{c|}{ Team management } & \multirow{2}{*}{ Sum of rows } \\
\cline { 3 - 5 } \multicolumn{2}{|c|}{} & yes & no & 28 \\
\hline \multirow{2}{*}{ Illegal operation } & yes & 14 & 14 & 29 \\
\cline { 2 - 5 } & no & 6 & 23 & $\mathrm{n}(57)$ \\
\hline \multicolumn{2}{|c|}{ Sum of columns } & 20 & 37 & $\chi^{2}=5.37, \quad \chi^{2}>\chi_{0.05}^{2}$, Non-independent \\
\hline \multicolumn{2}{|c|}{ Test results } & \multicolumn{2}{|c|}{$\chi^{2}$}
\end{tabular}

Table 13 The correlation analysis result between L2 and L1

\begin{tabular}{|c|c|c|c|c|}
\hline & \multicolumn{2}{|c|}{ The quality of personnel } & \multirow{2}{*}{ Sum of rows } \\
\hline & & yes & no & \\
\hline \multirow{2}{*}{$\begin{array}{c}\text { Perception and } \\
\text { decision-making errors }\end{array}$} & yes & 38 & 0 & 38 \\
\hline & no & 11 & 8 & 19 \\
\hline \multicolumn{2}{|l|}{ Sum of columns } & 49 & 8 & $\mathrm{n}(57)$ \\
\hline \multicolumn{2}{|l|}{ Test results } & \multicolumn{3}{|c|}{$\chi^{2}=18.61, \quad \chi^{2}>\chi_{0.05}^{2}$, Non-independent } \\
\hline
\end{tabular}


Table 14 The correlation analysis result between L2 and L1

\begin{tabular}{|c|c|c|c|c|}
\hline & & \multicolumn{2}{|c|}{ The quality of personnel } & \multirow{2}{*}{ Sum of rows } \\
\hline & & yes & no & \\
\hline \multirow{2}{*}{ Illegal operation } & yes & 27 & 1 & 38 \\
\hline & no & 22 & 7 & 29 \\
\hline \multicolumn{2}{|c|}{ Sum of columns } & 49 & 8 & $\mathrm{n}(57)$ \\
\hline \multicolumn{2}{|c|}{ Test results } & \multicolumn{3}{|c|}{$\chi^{2}=4.99, \quad \chi^{2}>\chi_{0.05}^{2}$, Non-independent } \\
\hline
\end{tabular}

\section{Conclusions}

From the analysis, it is found that the influence of enterprise is not the dominant factor in the accident and its influence on lower factors is limited. It is found obviously that inadequate supervision, the quality of personnel, perception and decision-making errors and illegal operation are the main related reasons. Safety training plays a crucial role for improving the quality of personnel and can improve safety awareness and safety knowledge of construction workers.

HFACS framework is no longer simply be classified based on hierarchical and array-based method of factors by the method of correlation analysis which is from top to bottom adjacent layer to find the relationship between factors. So the development of accident prevention measures according a certain factor will be more comprehensive and thorough.

\section{Acknowledgements}

This work was financially supported by the National Natural Science Foundation of China (No.51079078).

\section{References}

[1] Wang Yonggang, Wang Yan, Multidimensional analysis model of accident causes resulted from human factors, J. Traffic and Transportation Engineering. 8 (2000) 96-100.

[2] Dekker, S.W.A., The re-invention of human error, Human Factors Aerospace Safety. 1 (2001) 247-266.

[3] Wu Jianjun, Using Analytic Hierachy Process (AHP) in the Dangerous Source Assessment, J. Fuyang Teachers College Natural Science. 39 (1996) 47-50.

[4] Qian Xinming, Chen Baozhi, On identification \& control of major hazards, China Safety Science Journal. 4 (1994) 16-21.

[5] Li Jinlin, Zhao Zhongqiu, The Management Statistic, third ed., Tsinghua Univ. Press, Beijing, 2007.

[6] Weng Dingjun, The Social Statistic, third ed., Shanghai Univ. Press, Shanghai, 2006. 